\title{
MEASUREMENT OF SHORT PERIOD MOTION ON A FAST MOVING GLACIER AND ANALYSIS OF DATA
}

\section{(Abstract)}

\author{
by
}

\author{
K. Echelmeyer and B. Kamb
}

(California Institute of Technology, Pasadena, CA 91125, U.S.A.)

\section{ABSTRACT}

The investigation of glacier motion over short time periods for relatively long duration and over large longitudinal extent can yield valuable insight into the dynamics of glacier surging, basal sliding, ice stream development, and calving mechanisms. In this paper, we discuss techniques for monitoring short term horizontal and vertical motion employed on the often highly-fractured surface of Variegated Glacier, Alaska, prior to its recent surge (1980-84) and on the fast-moving outlet glacier - ice stream system of Jakobshavns Glacier, Greenland. The short period measurements described here were made continuously over one to several months, and, in many cases, encompass seasonal and longer term fluctuations as well. The positions of a relatively large number of surface markers (15-35) were followed as functions of time. Application of standard terrestrial surveying techniques and modern microwave and UHF positioning methods to these short period studies are discussed. We then describe methods of reduction and analysis on the resulting large data sats, which may be treated as quasi-stationary time series. Examples of correlation with other glacier variables, such as basal water pressure, seismicity, and stream discharge are given and the propagation of movement events discussed.

The meaning of the term 'short period' is relative to the size and mean velocity of an ice mass. On a small, fast-moving glacier, such as Variegated, close to the time of surge, speeds of 0.5 to $65 \mathrm{~m} /$ day allow accurate measurement of surface velocity, uplift, and strain over hourly time intervals. Motion studies over similar time periods may be accurately performed on lower Jakobshavns Glacier, where average speeds of $20 \mathrm{~m} /$ day are present. On the other hand, $50-70 \mathrm{~km}$ from terra firma on upper Jakobshavns Glacier, speeds are much reduced and stable control is difficult to establish. In a region such as this short period becomes daily to weekly, or even longer if absolute velocities are required.

Several factors are critical in the planning and successful completion of comprehensive short period motion study with a minimum of manpower. Choice of instrument type, location of control, marker construction and size, placement of markers on a highly-crevassed surface, and accuracy requirements all require careful consideration and are described in detail in this paper.

On Variegated and lower Jakobshavns Glaciers standard theodolites and electronic distance meters (EDM) were used to determine the horizontal and vertical position of a surface marker from either the glacier margin or from a moving control point, on the ice itself, whose location was simultaneously monitored. Mean flow azimuth and plunge were determined by complete surveys made daily or weekly. Shorter period surveys were often limited to the measurement of either distances only or angles only, depending on the component of motion along the line of measurement. Interpolation among these data sets for a given point yields accurate velocity, strain-rate, and vertical motion. The motion of a larger number of points could be determined from a few survey stations in this manner - for example, up to 30 markers were surveyed from 2 stations continuously over a three month period, covering a longitudinal distance of $15 \mathrm{~km}$ along the glacier.

Markers, consisting of poles drilled into the surface, metal and plastic tetrahedron, cloth drapes and dye bombs, were emplaced on foot, when feasible. At other times, however, the highly-fractured surface of these fast moving glaciers required deployment from a hovering helicopter. Many of the markers were equipped with fixed retro-reflecting prisms to facilitate EDM measurement. Remote light systems on control points allowed surveying during periods of darkness (when, invariably, interesting events tended to occur).

On upper Jakobshavns Glacier, markers were located using a microwave, or UHF, positioning system installed on board a helicopter. The decrease in accuracy of such measurements relative to standard methods required longer time periods between positioning, but, even at these lower frequencies, significant fluctuations were observed. Guidance capabilities of the positioning systems allowed rapid reoccupation of marker sites on the vast ice surface and also allowed rapid mapping of surface topography and terminus position.

Results show several interesting features of glacier dynamics: large fluctuations in velocity over periods of hours to days, rapid and substantial uplift of the surface, and the subsequent propagation of these movement events and kinematic-type waves along the surface; large seasonal DC shifts in velocity and interesting development of marginal and medial shear zones. Digitization and time-series analysis of the resulting data sets allow identification of significant periods of oscillation in glacier motion and quantitative description of the propagation of high-f requency disturbances. Correlation with continuous records of other variables on Variegated Glacier, observed by various investigators from University of Alaska and Washington and Caltech, such as borehole water level, seismicity, stream discharge, and small-scale strain and tilt, enables the first detailed observational description of a surging glacier to be made, and a detailed comparison with theoretical ideas.

A new amendment to Murphy's Law regarding such short period motion studies is also presented. 